\title{
The generalist solutionist
}

There are many problems people bring through my door. Some are straightforward - like a vessel discovered that cannot be unlocked. However, apparently simple requests can in fact, turn out to be more complicated. People may have tried them first with friends and family. Some like the idea of a challenge, and the activity it brings. I work on a few principles:

- be wary of assumptions;

- trust your instincts; and

- learn from experience and past mistakes.

It is hard to summarise the work of a 'general solutionist', but I will endeavour to explain a few of my skills.

\section{THE LOCKSMITH}

Locksmith skills one could argue are the foundation of our professional services. I have a range of keys for the purpose of opening locked vessels. For the most part, my keys serve me well, and over the years have become a faithful friend. Those used most have become sturdier with time, while others have long since turned to dust. Fortunately, although I do not possess every key, I still remember a good number of the locks and can refer to the Specialist Locksmith College where a full collection is stored and maintained. There is tension between the Specialist College and Members of the General Solutionist Association. We pass through their esteemed institution, collecting keys and knowledge, but we are not one of them. We view locksmith specialists as technicians of excellence, but not so skilled in life outside their institution walls. A famous general solutionist of yesteryear (now synonymous with time and poor record keeping) once said, 'It is not simply the quality of the key, but the skill and presentation behind the unlocking that makes the difference.' This is hard to standardise in the way a key is made, and can be dismissed as mere theatre. However, the vessel bearer generally appreciates seeing the show, and having a part to play. The final unlocking is rewarding for all if opinion and experience is sought, with discussion of the various keys available. Once opened, steps can be taken to prevent accidental locking in the future. It is satisfying to nurture the confidence and skill of a vessel bearer, but not all are comfortable with the responsibility, and some solutionists keep their knowledge a secret. I have heard rumour that specialist locksmiths present a selection of keys, pass comment on each one, and request the vessel bearer to make a choice. If a plea for assistance is made, they can face a wall of impassivity, and the utterance 'it is your decision, not mine to make.'

It sounds simple: a locked vessel requires unlocking with the correct key. However, it is unusual to have a perfect fit. There are universal themes associated with locks, but the mechanisms are exquisite in variety and detail. Foreign vessels hold their own particular challenges - without the right sequence of turns, and correct application of pressure, the key bearer will find frustration in failure despite the apparent correct key. When a vessel bearer enters dragging a weighty sack collected over time you know a challenge awaits. Ironically, the bearer will consider this preferable to causing bother on more than one occasion. As I sit, red of face and with a slight sweat, ploughing through various locks, my engagement dwindles, and they leave in a muddle with some vessels opened, some partially examined, and some needing further attention.

Occasionally I go through the motions of my performance, and the vessel opens to reveal ... another locked vessel. In the early days these little surprises would send me into a frantic scramble through various keys, much to the amusement, alarm or disdain of the owner. Nowadays I sit back, take a deep breath, and a measured response. The reason for the second or third locked vessel may simply reflect the complexity, but sometimes, it defies logic and hints towards the 'eternal lock', a legend akin to the existence of psychics and telepaths. Distinguishing an eternal lock from one of unusual complexity is problematic. The bearer can suffer disappointment to learn you are no longer willing to try another key. I offer support and understanding for those who carry the burden of the permanently sealed. They may seek a second opinion, or return with increasing frequency and concern, hoping my conviction might waver. In honesty I do at times suffer mind wanderings of doubt.

\section{BOMB DISARMAMENT}

My work is demanding, my resources finite. I aspire to offer the greatest skill to the greatest number. In the early days post apprenticeship, I used to sit with hands a-quiver on my trade tools, ready for rapid response. However, I have learnt, through bitter experience, to wait for the full nature of the problem to unfold.

Bomb disarmament is my least favourite role. The sound of ticking heightens a sense of limited time. It may present at any moment, sometimes among a sack of locked vessels. I have not yet had an explosion; I am here to tell the tale after-all! My initial response was near-panic. Is it the red wire? Do I have to disarm the timer first? Lately I have started to master a calm approach above my emotional turmoil. Despite temptation, I rarely attempt disarmament on first presentation. If it looks very close to detonation I will call the bomb experts. Otherwise, with permission, I perform an initial assessment and ask the person to return. To imagine someone carrying a bomb does not settle easy, but that is a professional burden to bear. However, on second viewing it often appears less intimidating. Bomb bearers may wish a second opinion, and at times they do not return, but through discussion with colleagues, I learn something of their story.

\section{MAP READER}

A term not to be confused with 'mindreader', of which I have heard talk, but alas, am not one. Occasionally I am gifted 
with something rather special. Usually folded neatly, and a little care-worn, the life map is hard to anticipate as it may be stored anywhere. Sometimes for example, this priceless document is concealed in a locked vessel, and we happen upon it together. Despite the weariness of time, hearing of the travels people have taken continues to delight. For map bearers, the quality of the journey may be most important, or the destination with promise of hidden treasure. I used to presume a solution would inevitably be sought; I have since learned an appreciative audience can be all that is desired. If invited, I may assist to orientate relative to the coordinates of the map, or give opinion on a particular route according to the hopes and fears of the traveller.

The role of general solutionist does not accommodate complete mastery; it is a craft fusing science and artistry, with endless opportunities for new skills and experience. The ill-defined borders, and borrowing from disciplines has called into question our worth. Outsiders of authority have examined the Profession with their measuring tools, and believe the component parts can be managed by others with different skills. We are not adverse to new ideas, and would not call ourselves general solutionists if adaptation and innovation were not part of our repertoire. We wait with rueful interest the outcome. In the meantime, I am proud to say I work in the space between things, wherein lies the immeasurable and misunderstood.

\section{Adrian Lamb}

DOI: 10.3399/bjgp10X514981

\section{RECIPE FOR MADNESS}

Inherit a base of genetic tendency Dust with ill-informed hedonism

Add a veneer of invincibility

Whip into a frenzy

Reduce to a gibbering wreck Drop into a sea of uncertainty Stew with a fog of insomnia Breathe in broken dreams

Embellish with whispered insecurities
Abandon all hope
Ignore past achievements
Drizzle a broken heart over it all
Serve bitter and lonely
Unkempt in torn clothes
In an atmosphere of mistrust
With a draught of ice-cold fear
Samir Dawlatly
DOI 10.3399/bjgp10X514990

Loch Eport is a magnificent sea loch on the east side of North Uist, $5733^{\prime} \mathrm{N} 0710^{\prime} \mathrm{W}$, where Back Pages columnists retire to contemplate at midsummer. The hill to the south is Heaval, the highest point on the island, nomenclature routinely Viking. For one member of the crew the name of the loch kept morphing into Eportfolio, for which some members of RCGP UK Council bear a direct responsibility and they should be ashamed. Note exquisite pink wildflowers in the foreground, on the salty foreshore. What are they? Where is Richard Lehman when you need him? As we left at 0520 on a June morning, through the narrow but deep entrance channel, two eagles soared above us. It really doesn't get any better!

\section{Alec Logan}

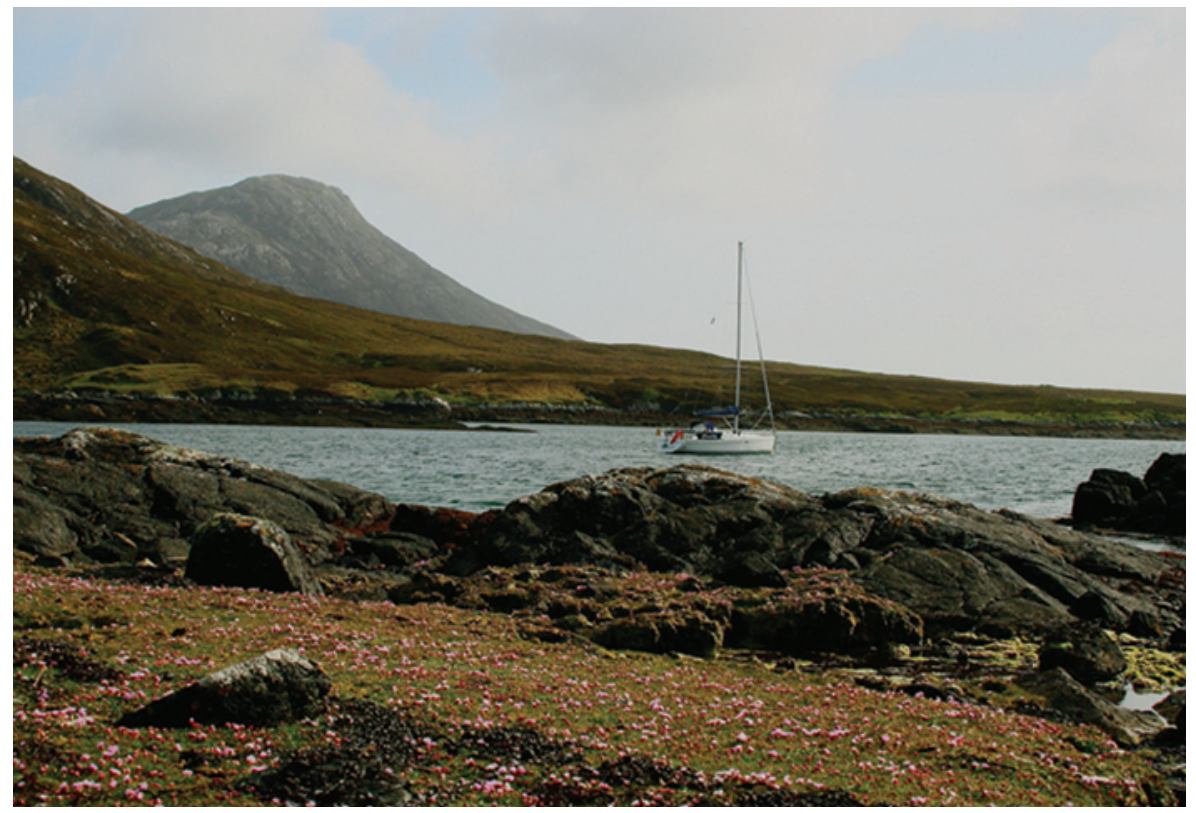

